\title{
Research on Inflation Situation of Dual Economic Countries Based on Transmission Mechanism of Financial Crisis
}

\author{
Jianshi Yang \\ Xi'an University of Arts and Science, Xi'an, China \\ yang_shijian@126.com
}

Keywords:financial crisis conduction; dual economy; inflation; maint model; SPLM statistical software; curve fitting

\begin{abstract}
The loss results from inflation which caused by the financial crisis is often greatly exceeded people's expectation. The crisis not only damages the country's financial market but also influences the world's financial market, and even developed into a worldwide financial crisis. It is important to establish transmission mechanism of financial crisis to warn financial crisis and conduction relationship of inflation caused by inflation among nations. This paper establishes the CPI, PPI, and GDP comprehensive evaluation model according to Maint binary economic development model. Then, it establishes the payments, exchange rate, foreign trade and industry conduction mechanism using weighted average change model to forecast inflation. Finally, it uses of statistical software SPLM to fit survey data. At last, it draws out the curve of the data which is the influence of international financial crisis on the bank, the player of domestic market and the stock market. It provides a theoretical basis for the transmission mechanism of financial crisis brought by national inflation.
\end{abstract}

\section{Introduction}

The typical characteristic of dual economy is uncoordinated development of urban and rural. Urban industry developed faster than rural agriculture. The prices of industrial products are higher than agricultural products. China is a typical dual economy country which not only restricted the long-term economic development of our country, but also had a profound impact on inflation and macro-control of economic[1-3]. This paper first introduces the economic characteristics of the dual economy countries. Then, it explains the differences between the dual economy countries and the international average by the rate of capital formation and final consumption rate. The second part of the paper analyzes the characteristics of the Maint economic model[4,5]. The third part forecasts inflation mathematical model through the model of weighted average and establishes mathematical model of the financial transmission mechanism. Finally, it analyzes the impact of the international financial crisis on the exchange rate and stock index using professional statistical analysis software of SPLM software. Eventually, it gets the chart of exchange rate and stock index under the influence of the financial transmission mechanism which provides a theoretical reference for the inflation financial conduction mechanism of dual economy.

\section{Economic characteristics of the dual economic nation}

The characteristic of economy of dual economic nation is the uncoordinated development of agricultural economy and non-agricultural economy. The value of industrial products is high. The agricultural economy develops slowly, and the value of agricultural products is low[6]. The characteristic of dual economy can measure the economic characteristics by the dual contrast coefficient. The dual contrast coefficient indicates the ratio of the agricultural labor and nonagricultural labor and the output value of the agricultural labor and non- agricultural labor. If dual coefficient is large, the difference between agriculture and non-agriculture is the largest. When the coefficient is close to 1 , economic duality is more unobvious. The dual economy is more obvious when the coefficient is smaller. 


\begin{tabular}{|c|l|l|}
\hline Years & Capital formation rate & Final consumption rate \\
\hline $\mathbf{2 0 0 9}$ & $40.2 \%$ & $55.6 \%$ \\
\hline $\mathbf{2 0 1 0}$ & $43.1 \%$ & $52.3 \%$ \\
\hline $\mathbf{2 0 1 1}$ & $42.2 \%$ & $51.5 \%$ \\
\hline $\mathbf{2 0 1 2}$ & $\mathbf{4 1 . 3 \%}$ & $52.7 \%$ \\
\hline
\end{tabular}

Table 1 is the capital formation rate and final consumption rate of China from 2009 to 2012.From the Table, we can see that the highest rate of capital formation is in 2010 , and the lowest is $40.2 \%$. The highest final consumption rate is $55.6 \%$, and the lowest consumption rate is $51.5 \%$. According to the data provided by the World Economic Organization, the world average final consumption rate is $79.1 \%$ in 2012 . The final consumption rate of our country is lower compared with the world average level which mainly because of the impact of the dual economy and the lower level of consumption in villages and towns.

\section{Maint dual economic development model}

The characteristic of Maint dual economic development model contains four areas: product markets, capital markets, labor markets, and administrative departments[7].

Duality of products is mainly reflected in three aspects: wholesale and retail prices of the towns and cities are very different. The price of same product in different areas is not the same influenced by the local environment. The volatility of agricultural products is large.

Duality of capital market is mainly reflected in: the difference between Capital-effective orderly market and disorderly market is large. Efficiency is reflected in the cost of interest rates which include transaction costs and interest. The unordered capital market is chaotic and has no unified capital efficiency.

Duality of labor market is mainly reflected in: the wages of each sector are not the same[8]. The wage of scientific and technological sector and professional and technical class are relatively higher while traditional manual labor markets' are relatively lower. The differences of labor wages are large. The binary nature of the government's financial sector mainly reflected as the differences of urban areas and rural areas[9]. The city is generally composed by a number of large and medium-sized enterprises which can lead by government departments unified. The enterprises of towns are small which need intermediate organizations to lead.

\section{Forecasting inflation by weighted average change method}

Inflation indicators can be used to represent the general price level. Price level index formula most common used can be expressed as linear indicator[10]:

$$
W_{k}=T \sum_{j=1}^{100} l_{j} \frac{U}{U_{o}}
$$

In this formula, $\sum_{j=1}^{100} l_{j}=1 W_{k}$ is the overall price level of $\mathrm{k}$-th stage. $\mathrm{T}$ is basic price. At the beginning, it is 100. $U$ is price weight of k-th stage. Assuming that $U_{t}$ is price level of one period. Price level of $\mathrm{k}$ period is the total of the price level of one period and price changes of $\mathrm{k}$ period which is shown as[11]:

$$
W_{k}=U_{t}+T \sum_{j=1}^{100} l_{j} \frac{U}{U_{o}}-U_{t}=U_{t}+T \sum_{j=1}^{100} l_{j} \frac{U-U_{t}^{0}}{U_{o}}=U_{t}+T \sum_{j=1}^{100} l_{j} \frac{\Delta U}{U_{o}}
$$

The weight ${ }_{j}$ can be calculated by the weighted average change method:

$$
l_{j}=\frac{U_{o} X_{o}}{\sum_{i=1}^{n} U_{o 1} X_{o 1}}
$$

$X$ is the total sales of a commodity. We can substitute (3) into (1): 


$$
\hat{W}=\frac{\sum_{i=1}^{n} U_{o} X_{o}}{\sum_{i=1}^{n} U_{o 1} X_{o 1}} \times T
$$

We can calculate the CPI index of any one stage by using the price level indicator getting from weighted average change model above.

We can calculate the CPI index of any one stage by using the price level indicator getting from weighted average change model above which is shown in Figure 1. From it, we can see that the volatility of CPI change indicators is obvious which display changes of CPI perfectly.

\section{Conduction mechanism of financial crisis}

Quantification of transmission mechanism of finance can be expressed by time serie. When the financial conduction changes changes with time,we can find the relationship of conduction amount with time.But The time serie is a variable. In the case of a variety of sequence, the financial transmission submits multiple linear regression. Assuming that there is a quantitative relationship between q1a and q2a:

In this formula, a is time. Assuming that the relationship of the two variables $q 1 \mathrm{t}, \mathrm{q} 2 \mathrm{t}$ is as follows:

$$
\left\{\begin{array}{c}
\mathrm{q}_{1, \mathrm{t}}=\mathrm{u}_{1}+\pi_{11} q_{1, a-1}+\pi_{12} q_{2, a-1}+v_{1} \\
\mathrm{q}_{2, \mathrm{t}}=\mathrm{u}_{2}+\pi_{21} q_{1, a-1}+\pi_{22} q_{2, a-1}+v_{2}
\end{array}\right.
$$

It can be expressed as matrix for $[13,13]$ :

$$
\left[\begin{array}{l}
q_{1 a} \\
q_{2 a}
\end{array}\right]=\left[\begin{array}{l}
u_{1} \\
u_{2}
\end{array}\right]+\left[\begin{array}{ll}
\pi_{11} & \pi_{12} \\
\pi_{21} & \pi_{22}
\end{array}\right]+\left[\begin{array}{l}
q_{1, a-1} \\
q_{2, a-1}
\end{array}\right]+v\left[\begin{array}{l}
v_{1 t} \\
u_{2 t}
\end{array}\right]
$$

If

$\mathrm{Q}_{\mathrm{a}}=\left[\begin{array}{l}q_{1 t} \\ q_{2 t}\end{array}\right], U=\left[\begin{array}{l}u_{1} \\ u_{2}\end{array}\right], P i=\left[\begin{array}{ll}\pi_{11} & \pi_{12} \\ \pi_{21} & \pi_{22}\end{array}\right], v_{a}=\left[\begin{array}{c}v_{1 a} \\ v_{2 a}\end{array}\right] \mathrm{Q}_{\mathrm{a}}=u+P_{i 1} Q_{a-1}+v_{a}$

The variable containing $n$ time serie can be expressed as[14] :

$$
\mathrm{Q}_{\mathrm{a}}=\mathrm{u}+\mathrm{P}_{\mathrm{i} 1} \mathrm{Q}_{\mathrm{a}-1}+\mathrm{P}_{\mathrm{i} 2} \mathrm{Q}_{\mathrm{a}-2}+\ldots+\mathrm{P}_{\mathrm{ic}} \mathrm{Q}_{\mathrm{a}-\mathrm{c}}+\mathrm{v}_{\mathrm{a}}
$$

In this formula,

$$
\mathrm{Q}_{\mathrm{a}}=\left(\mathrm{q}_{1, \mathrm{a}} \quad \mathrm{q}_{2, \mathrm{a} \ldots} \mathrm{q}_{\mathrm{n}, \mathrm{a}}\right)^{\prime}, \mathrm{u}=\left(\mathrm{u}_{1} \mathrm{u}_{2} \ldots \mathrm{u}_{\mathrm{n}}\right)^{\prime}
$$

Then, we can get the following matix:

$$
\mathrm{Pi}_{\mathrm{i}}=\left[\begin{array}{cccc}
\pi_{11 i} & \pi_{12 i} & \cdots & \pi_{1 n i} \\
\pi_{21 i} & \pi_{22 i} & \cdots & \pi_{2 n i} \\
\vdots & \vdots & \ddots & \vdots \\
\pi_{n 1 i} & \pi_{2 n i} & \cdots & \pi_{n n i}
\end{array}\right]
$$

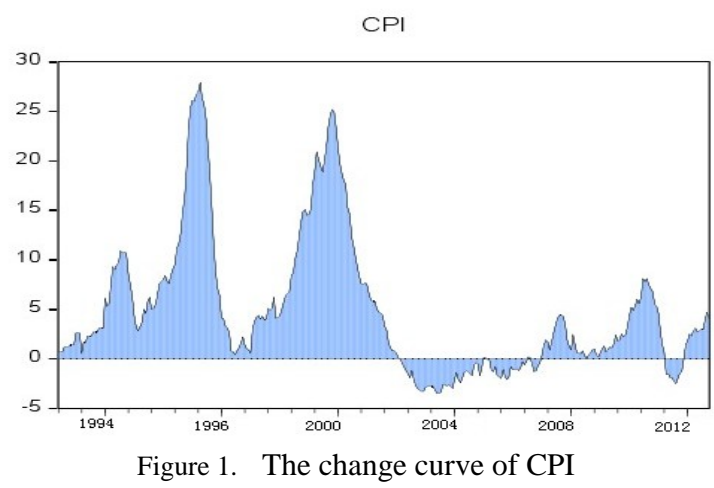

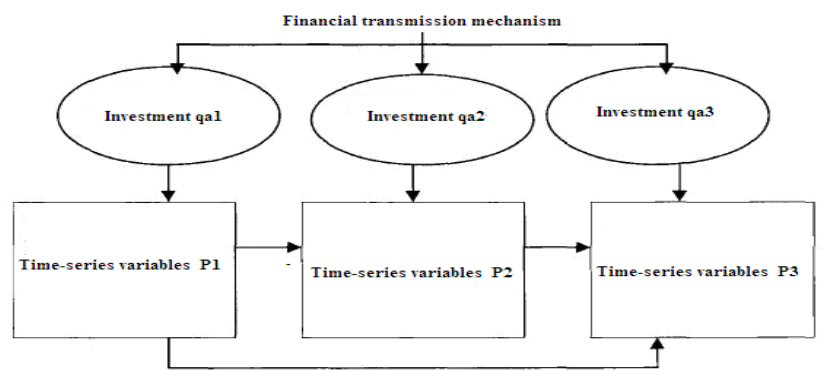

Figure 2. The diagram of financial transmission mechanism

The relationship diagram of the conduction mechanism of finance can be expressed as Figure 2 . This paper uses multivariate to calculate the comprehensive benefits. Each variable relationship can be expressed by the model formula. We can find the financial conduction relationship by calculating the optimal solution. 


\section{SPLM conduction mechanism of the financial crisis and statistical analysis of inflation}

The SPLM Software is professional statistical analysis software[15]. This paper imports statistical data into SMLM software and investigates it. It first studies the inflation from the inflation tax mechanism.

TABLE II. THE INFLATION TAX OF DUAL NATION

\begin{tabular}{|c|l|l|c|}
\hline Country & $\begin{array}{c}\text { The percentage of expansion } \\
\text { tax in GNP \% }\end{array}$ & $\begin{array}{c}\text { The percentage of currency } \\
\text { in GNP \% }\end{array}$ & $\begin{array}{c}\text { Expansion } \\
\text { Rate \% }\end{array}$ \\
\hline Argentina & 5.1 & 6.1 & $152.1 \%$ \\
\hline Mexico & 4.2 & 5.2 & $128.3 \%$ \\
\hline Peru & 3.0 & 4.1 & $112.1 \%$ \\
\hline Turkey & 2.2 & 3.2 & $98.3 \%$ \\
\hline Philippines & 1.3 & 3.1 & $75.2 \%$ \\
\hline
\end{tabular}

From Table 2, we can see that the inflation tax cannot solve the problem of inflation perfectly. Factor affecting inflation is mainly the currency in circulation. If currency in circulation is bigger, inflation is more likely to occur. If the liquidity is smaller, the inflation rate is smaller.

Figure 3 imported the statistical analysis data into mathematical model of conduction mechanism of the financial crisis through SPLM software and obtained the influence of conduction mechanisms of the financial crisis on the exchange rate. From the Figure, we can see that in the financial crisis, the exchange rate began to decline and reached the lowest at last[16].

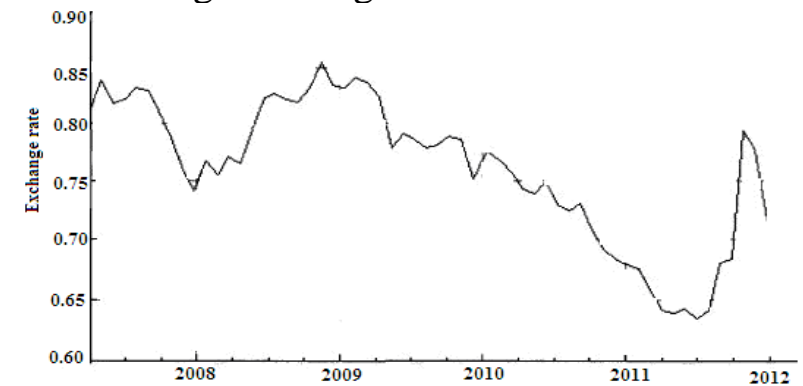

Figure 3. The influence of the transmission mechanism of financial crisis on exchange rate

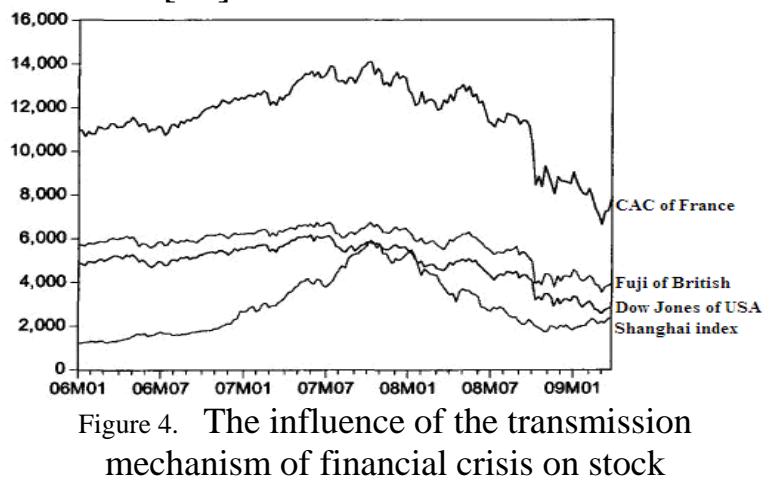

mechanism of financial crisis on stock

Table 4 imported the statistical analysis data into mathematical model of conduction mechanism of the financial crisis through SPLM software and obtained the influence of conduction mechanisms of the financial crisis on the stock index. From the Figure, we can see that in the financial crisis, the stock index began to decline. It proved that there is a direct impact of the financial transmission mechanism on stock index.

\section{Conclusion}

This paper studied the dual economic inflation and financial transmission mechanism. The first part introduced the characteristics of dual economy in detail. It defined the Dual economy metrics according to the rate of capital formation and final consumption rate, and the contrast coefficient. Then, it introduced Maint dual economy model. The third part established the mathematical model of inflation by the weighted average method and the mathematical model of the financial transmission mechanism through VAR theory. Finally, this paper imported the statistical analysis data into mathematical model of conduction mechanism of the financial crisis through SPLM software and obtained the influence of conduction mechanisms of the financial crisis on the exchange rate and stock index. From the analysis of data, we can find that the transmission mechanism of financial crisis impacts the exchange rate and the stock directly, which makes the reduction of the exchange rate and stock index and provides reliable theoretical basis for the research of dual economy inflation and the financial transmission mechanism.

\section{References}

[1] Ridong Hu,Zhifang Su. Nonlinear relationship between urbanization and Chinese inflation and uncertainty of inflation. Economic and Technical Economic Research,2012(02):21-23

[2] Yiping Huang, Xun Wang, Xiuping Hua. Determinants of inflation in China. Financial Research, 2010 (06):23-24

[3] Cheng Li, Bin Wang, Wentao Ma. Cycle fluctuations of international oil prices and inflation. 
Statistical Research, 2010 (04):34-35.

[4] Hao Li, Shaoping Wang. Expectations and stickiness of inflation. Statistical research, 2011(01):21-22

[5] Hong Liu, Guolin Jiang. Model selection and empirical research on explanation of inflation. Quantitative Economics Research, 2009(01):45-46

[6] Jiancheng Pan, Shilei Tang. How the confidence affect inflation. Statistical Research,2010 (10):23-25.

[7] Zhifang Su. The expectations uncertainty, structured or impact-type of China's inflation. Quantitative and Technical Economic Research,2010 (12):23-27.

[8] Bin Wang, Cheng Li, Wentao Ma. Spillovers and dynamic correlation of international oil prices and inflation. Finance and Economics,2010 (04):43-45.

[9] Xindong Zhao, Peng Geng. Study on causes of China's inflation. Quantitative and Technical Economic Research, 2010(10):45-46.

[10] Research group of China's economic growth and macroeconomic stability. External shocks and inflation of China. Economic Research,2012 (05):45-49

[11] Fengyang He, Jianping Liu. Before and after the financial crisis, path analysis of China's CPI - based on empirical studies of the structure catastrophe theory . Sankei Comments, 2010(1):106-113.

[12] Wenbo Li, Zhiyuan Lin,Hua Guo. Analysis and forecast of China's macroeconomicliquidity excess of China in the context of globalization.Economic Science Press, 2008:147-150

[13] Ming Zhang. Transmission mechanism of subprime mortgage crisis . International Economic Review, 2010(12):32-36.

[14] Hong Wu. Path analysis of financial crisis to the economic crisis. Wuhan Metallurgical Management Institute,2009,19(2):3-6

[15] Xue Li. Research on the financial crisis based on experimental economics. Research Market Modernization, 2009(12):21-22.

[16] Campbell R. Harvey. The Financial Crisis of 2008: What Needs to Happen after TARP . Social Science Research Network, 2008(12):1135-1145. 